\title{
Food Insecurity and Intimate Partner Violence among Rural Women, Minia, Egypt
}

\author{
Eman Mohamed Mahfouz, Eman Sameh Mohamed, Shaza Fadel Alkilany, Tarek \\ Ahmed Abdel Rahman
}

Department of Public Health, Faculty of Medicine, Minia University, El-Minia, Egypt

Submission Date: 2020-12-31 Revision Date: 2021-01-25 Acceptance Date: 2021-01-25

\begin{abstract}
Background: Food insecurity and violence exposure are evolving public health problems among women worldwide including Egypt. Food insecurity is one of the household stressors which may be linked to intimate partner violence (IPV), which is often underreported, spuriously affecting the magnitude of these relationships. Objective: To determine the prevalence of IPV, and its interlink with food insecurity. Method: A comparative cross-sectional study was conducted among a representative sample of Egyptian households from a rural area in Upper Egypt during 2018. The study included 380 married women; their age ranged from 19 to 35 years. Interviewer-administered questionnaire was used to collect the data on socioeconomic status and violence exposure. Household Food Insecurity Access Scale (HFIAS) was administered. Results: About one fourth of studied women reported violence exposure. Approximately $70 \%$ of women in the study reported food insecurity, with $15.3 \%, 37.4 \%$ and $17.1 \%$ reporting mild, moderate and severe food insecurity respectively. Results of multivariate logistic regression showed that food insecurity, women's education and husband's occupation were predictors of IPV. Women from food insecure households were 4 times more likely to experience IPV than their counterparts in food secure households $(95 \% \mathrm{CI}=2.03-9.25)$. Conclusion: being food insecure puts women at greater risk of IPV exposure perpetrated by their husbands. Policy maker should improve national food security programs. Interventions to empower women socially and economically is also recommended.
\end{abstract}

Keywords: IPV, Violence, Women, Food Insecurity, Egypt

Corresponding author: Tarek A Abdel Rahman E-mail address: tarek1.mohamed@mu.edu.eg

\section{Introduction}

Intimate Partner Violence (IPV) is a serious public health problem facing women globally and in Egypt. According to world health organization, violence against women is a fundamental violation of women's human rights. ${ }^{1}$

Physical violence perpetrated by men toward women is common. Approximately one fourth of evermarried women experienced physical IPV at least once by their husbands, and most instances perpetrated against less educated and with less income women. ${ }^{2}$
In Egypt, about one fourth of married women have been exposed to spousal violence and rising to $29.1 \%$ in rural Upper Egypt. $^{3}$

Despite international efforts, violence against women continues to be common and erroneously tolerated within many societies in developing countries in general and Arab countries as a cultural norm, the prevailing socioeconomic and cultural factors that encourage a culture of violence against women or through misinterpretation of religious rules. 
Violence against women may not only compromise the quality of life of women and children but also is a hidden obstacle for the economic and social development of countries. ${ }^{4}$

Recently food insecurity has been introduced as a risk factor for IPV. ${ }^{5}$ Food insecurity is defined as existing when people lack secure access to a sufficient quantity of affordable, nutritious food. The magnitude of the relationship between food insecurity and IPV may be attenuated because IPV is often underreported. $^{6}$

Poverty has been associated with violence perpetration. Food insecurity is closely related to poverty and through mechanism related to gender role, men perpetrate violence against women. ${ }^{7}$

Among married women, being food insecure is associated with higher odds of certain types of violence as determined in some aspects by Women's status, level of empowerment, financial hardship and economic independence. Poor Women with financial hardship and economic dependence might lose autonomy and decision-making power in their relationships to refuse or leave an abusive relationship. On the other hand, financial difficulties might act as a driver for IPV thought mechanisms related to stress. ${ }^{8}$

HFI (Household Food Insecurity) is often a key marker of violence vulnerability, even in high-income countries. ${ }^{9}$ Physical violence was more likely to be experienced among food insecure households than food secure counterparts. ${ }^{5}$ Economic hardship, being unable to cope with difficulty due to unavailable resources; and the mental distress caused by food insecurity could contribute to high frequency and intensity of conflict between parents which eventually lead to intimate partner violence. ${ }^{10,11}$ Women are at a greater risk of experiencing food insecurity due to many macro-structural reasons including power inequality. ${ }^{12}$

The relationship between IPV and food insecurity is bidirectional. Physical violence was more likely to be experienced among food insecure households than food secure counterparts. ${ }^{5}$ On the other hand, IPV can lead to food insecurity through impairing mother's ability to manage obtaining adequate food mediated by negative impact on mental health or through economic abuse and controlling access to financial resources. ${ }^{5,12,13}$ Furthermore, this psychological disturbance provoked by violence may affect eating practices including loss of appetite, abdominal pain, diarrhea or constipation and eating disorders putting women victims of violence at risk of malnutrition. ${ }^{11}$

IPV is associated with women's poor health. Women who experience IPV are more likely to be depressed, liable to suicidal thoughts and attempts, have post-traumatic stress disorder, and have overall worse health. ${ }^{9}$

A rich body of research confirms a strong association between mother's exposure to domestic violence and poor nutritional outcomes of her children. ${ }^{14}$ Violence can lead also to stress, depression, and poor physiological and psychological, behavioral and social outcomes for women and their children, which can indirectly affect nutrition. ${ }^{13,14}$ The link between food insecurity and violence has received little attention, which necessitates addressing it by research. To the best of our knowledge, no previous studies have investigated relationship specifically in Minia one of the Egyptian governorates so far.

The objective of the present study is to determine the prevalence of IPV, and to investigate its association with food insecurity.

\section{Method}


Study design and participants: This is a was conducted among a representative comparative cross-sectional study that

Table (1): Characteristics of studied married women aged 18-35 years

\begin{tabular}{|c|c|c|}
\hline & & All women \\
\hline & & $\mathrm{N}=380(100 \%)$ \\
\hline Age (years) & $\begin{array}{l}\text { Mean } \pm \text { SD } \\
\text { (Range) }\end{array}$ & $\begin{array}{c}26.9 \pm 3.7 \\
(19-35)\end{array}$ \\
\hline Women's occupation & Housewife & $348(91.6)$ \\
\hline & Working & $32(8.4)$ \\
\hline Women's education & Illiterate & $70(18.4)$ \\
\hline & Below secondary & $63(16.6)$ \\
\hline & Secondary & $220(57.9)$ \\
\hline & University or higher & $27(7.1)$ \\
\hline Family size & $\begin{array}{l}\text { Mean } \pm \text { SD } \\
\text { (Range) }\end{array}$ & $\begin{array}{l}5.8 \pm 2.8 \\
(3-28)\end{array}$ \\
\hline Number of children & $\begin{array}{l}\text { Mean } \pm \text { SD } \\
\text { (Range) }\end{array}$ & $\begin{array}{l}2.7 \pm 1.2 \\
(1-7)\end{array}$ \\
\hline Household income & In debt & $42(11.1)$ \\
\hline & Just meet routine expenses & $60(15.8)$ \\
\hline & Meet routine expenses and emergencies & $138(36.3)$ \\
\hline & Able to save money & $140(36.8)$ \\
\hline Husband's education & Illiterate & $53(13.9)$ \\
\hline & Below secondary & $74(19.5)$ \\
\hline & Secondary & $213(56.1)$ \\
\hline & University or higher & $40(10.5)$ \\
\hline Husband's occupation & Unemployed & $5(1.3)$ \\
\hline & Unskilled worker & $81(21.3)$ \\
\hline & Skilled & $208(54.7)$ \\
\hline & Trades/business & $38(10)$ \\
\hline & Semiprofessional & $26(6.8)$ \\
\hline & Professional & $22(5.8)$ \\
\hline Husband & Present & $245(64.5)$ \\
\hline & Working abroad & $135(35.5)$ \\
\hline Smoker husband & & $199(52.4)$ \\
\hline Socio-economic & Very low $(<35)$ & $77(20.3)$ \\
\hline quartiles & Low $(35-41)$ & $91(23.9)$ \\
\hline & Middle (42-47) & $110(28.9)$ \\
\hline & High $(\geq 48)$ & $102(26.8)$ \\
\hline $\begin{array}{ll}\text { Past-year } & \text { family } \\
\text { stressors } & \end{array}$ & Yes & $97(25.5)$ \\
\hline Stressor type & Surgical operations & $58(15.3)$ \\
\hline & Financial problem/ being in debt & $17(4.5)$ \\
\hline & Treatment costs & $7(1.8)$ \\
\hline & Job loss & $5(1.3)$ \\
\hline & Illness of family member & $5(1.3)$ \\
\hline & Accidents/injuries of family member & $3(0.8)$ \\
\hline & Gambling & $1(0.3)$ \\
\hline & House burnt down & $1(0.3)$ \\
\hline IPV exposure & Yes & $98(25.8)$ \\
\hline
\end{tabular}

\begin{tabular}{lllll}
\hline The Egyptian Journal of Community Medicine & Vol. 39 & No. 3 & July & 2021
\end{tabular}


Table (2): Comparison of sociodemographic characteristics according to according to violence exposure by women

\begin{tabular}{|c|c|c|c|}
\hline & $\begin{array}{c}\begin{array}{c}\text { Women with } \\
\text { experiences of } \\
\text { violence }\end{array} \\
\mathbf{N}=\mathbf{0 8} \\
\end{array}$ & $\begin{array}{c}\begin{array}{c}\text { Women without } \\
\text { experiences of } \\
\text { violence }\end{array} \\
\mathbf{N}=282 \\
\end{array}$ & $p$ value \\
\hline & $\mathbf{N}=98$ & $\mathrm{~N}=\mathbf{2 8 2}$ & \\
\hline Age & $\begin{array}{c}27.1 \pm 3.3 \\
(19-33)\end{array}$ & $\begin{array}{c}26.9 \pm 3.8 \\
(19-35)\end{array}$ & 0.634 \\
\hline Number of children & $\begin{array}{c}2.7 \pm 1.2 \\
(1-7)\end{array}$ & $\begin{array}{c}2.7 \pm 1.1 \\
(1-6)\end{array}$ & 0.085 \\
\hline \multicolumn{4}{|l|}{ Women's education } \\
\hline Illiterate & $31(44.3 \%)$ & $39(55.7 \%)$ & \multirow{3}{*}{$<0.001 *$} \\
\hline Below secondary & $12(19 \%)$ & $51(81 \%)$ & \\
\hline Secondary or above & $55(22.3 \%)$ & $192(77.7 \%)$ & \\
\hline \multicolumn{4}{|l|}{ Women's occupation } \\
\hline Housewife & $91(26.1 \%)$ & $257(73.9 \%)$ & \multirow{2}{*}{0.597} \\
\hline Working & $7(21.9 \%)$ & $25(78.1 \%)$ & \\
\hline Family size & $\begin{array}{c}6.5 \pm 3.6 \\
(3-21) \\
\end{array}$ & $\begin{array}{l}5.5 \pm 2.5 \\
(3-28)\end{array}$ & $0.003 *$ \\
\hline \multicolumn{4}{|l|}{ Household income } \\
\hline $\begin{array}{l}\text { In debt } \\
\text { Just meet routine expenses } \\
\text { Meet routine expenses and } \\
\text { emergencies } \\
\text { Able to save money }\end{array}$ & $\begin{array}{r}19(45.2 \%) \\
18(30 \%) \\
43(31.2 \%) \\
18(12.9 \%)\end{array}$ & $\begin{array}{r}23(54.8 \%) \\
42(70 \%) \\
95(68.8 \%) \\
122(87.1 \%)\end{array}$ & $<0.001 *$ \\
\hline \multicolumn{4}{|l|}{ Husband's education } \\
\hline $\begin{array}{l}\text { Illiterate } \\
\text { Below secondary } \\
\text { Secondary or above }\end{array}$ & $\begin{array}{l}26(49.1 \%) \\
22(29.7 \%) \\
50(19.8 \%)\end{array}$ & $\begin{array}{r}27(50.9 \%) \\
52(70.3 \%) \\
203(80.2 \%) \\
\end{array}$ & $<0.001 *$ \\
\hline \multicolumn{4}{|l|}{ Husband's occupation } \\
\hline $\begin{array}{l}\text { Unemployed/ Unskilled worker } \\
\text { Skilled worker } \\
\text { Trades/business } \\
\text { Semiprofessional/ Professional }\end{array}$ & $\begin{array}{r}32(37.2 \%) \\
56(26.9 \%) \\
8(21.2 \%) \\
2(4.2 \%) \\
\end{array}$ & $\begin{array}{r}54(62.8 \%) \\
152(73.1 \%) \\
30(78.9 \%) \\
46(95.8 \%) \\
\end{array}$ & $<0.001 *$ \\
\hline \multicolumn{4}{|l|}{ Husband } \\
\hline $\begin{array}{l}\text { Present } \\
\text { Working abroad }\end{array}$ & $\begin{array}{l}71(29 \%) \\
27(20 \%)\end{array}$ & $\begin{array}{l}174(71 \%) \\
108(80 \%)\end{array}$ & 0.055 \\
\hline Smoker husband & $61(30.7 \%)$ & $138(69.3 \%)$ & 0.023* \\
\hline \multicolumn{4}{|l|}{ Socio-economic quartiles } \\
\hline $\begin{array}{l}\text { Very low }(<35) \\
\text { Low }(35-41) \\
\text { Middle }(42-47) \\
\text { High }(\geq 48) \\
\end{array}$ & $\begin{array}{r}38(49.4 \%) \\
22(24.2 \%) \\
29(26.4 \%) \\
9(8.8 \%) \\
\end{array}$ & $\begin{array}{l}39(50.6 \%) \\
69(75.8 \%) \\
81(73.6 \%) \\
93(91.2 \%) \\
\end{array}$ & $<0.001 *$ \\
\hline Past-year family stressors & $33(34 \%)$ & $64(66 \%)$ & $0.032 *$ \\
\hline
\end{tabular}

*Significant level at $p$ value $<0.05$

aged 19 to 35 years were interviewed.

Using cluster sampling method, the village was divided into four regions in the four-direction starting from a fixed point (the rural health unit), in each region, house-to-house survey was conducted until the required sample size was reached. Eligible criteria included married woman aged 15-35 years. 
Table (3): Household food insecurity and its relation to intimate partner violence

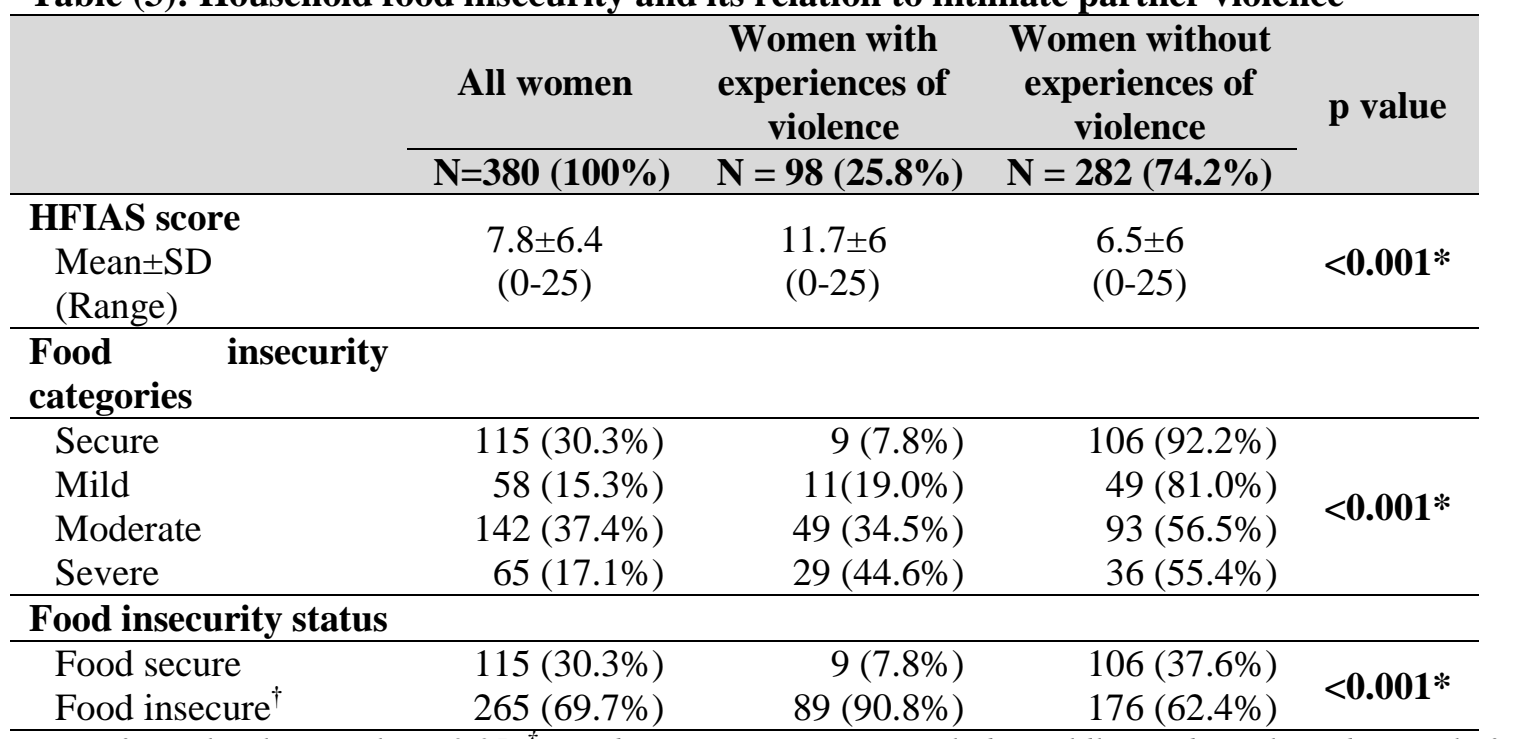

*significant level at $p$ value $<0.05,{ }^{\dagger}$ Food insecurity category includes mildly, moderately and severely food insecure

Eligible women refused participation were excluded. The study participants were grouped and compared based on history of violence exposure.

Women were interviewed face to face in the household setting using a multicomponent questionnaire. The questionnaire covered information on socio-demographic characteristics, violence exposure, past-year family stressors and the household food security status. Interviews lasted on average 20 min per household.

The items in the questionnaire included:

Physical IPV was assessed in the last 12 months with a question derived from the Conflict Tactics Scales (CTS ) ${ }^{(15)}$. Women reported whether her partner hit, slapped or used some other physical force against her when he is angry.

Socio-economic status (SES) was calculated according to El-Gilany et al. (2012), ${ }^{16}$ a modification of the old scale developed by Fahmy and El-Sherbini (1983). ${ }^{17}$ The scale has 7 domains with a total score of 84 , with a higher score indicating better SES. Total score was calculated by summing the score of the 7 domains: Education and cultural,
Occupation, Family, Family possessions, Economic, Home sanitation, Health care.

The Household Food Insecurity Access Scale (HFIAS): HFIAS was used to assess the food security status of the participants' households. The HFIAS was developed by the US Agency for International Development (USAID) and funded Food and Nutrition Technical Assistance (FANTA) Project. ${ }^{18}$ Validity and reliability of Arabic version of the HFIAS was validated in rural Lebanon and was found to be a valid and reliable instrument to assess household food insecurity. ${ }^{19}$

The scale includes nine questions. The score is a quantitative measure of the degree of household food insecurity (access) during the past month. The HFIAS score is calculated for each household by summing the codes for each frequency-of-occurrence question. The total score ranges from 0 to 27 , the higher the score, the more household food insecurity (access) is evident. Households can be categorized according to HFIAS into four levels of household food insecurity: food secure, and mild, moderately and severely food insecure. ${ }^{18}$ The required sample size was calculated 
Table (4): Univariate and multivariate binary logistic regression analyses of factors predicting exposure to intimate partner violence

\begin{tabular}{|c|c|c|c|c|}
\hline \multirow[b]{2}{*}{ Dependent variable: IPV } & \multicolumn{2}{|c|}{ Univariate analysis } & \multicolumn{2}{|c|}{ Multivariate analysis } \\
\hline & $\begin{array}{c}\text { Crude OR }(95 \% \\
\text { CI) }\end{array}$ & $p$ value & $\begin{array}{l}\text { Adjusted OR } \\
(95 \% \mathrm{CI})\end{array}$ & $p$ value \\
\hline \multicolumn{5}{|l|}{ Food security status } \\
\hline Food secure & 1.00 (reference) & \multirow[b]{2}{*}{$<0.001 *$} & 1.00 (reference) & \multirow{2}{*}{$<0.001 *$} \\
\hline Food insecure & $5.96(2.88-12.32)$ & & $5.04(2.32-10.96)$ & \\
\hline \multicolumn{5}{|l|}{ SES } \\
\hline Very low & $10.07(4.45-22.80)$ & $<0.001 *$ & & \\
\hline Low & $3.30(1.43-7.60)$ & $0.005^{*}$ & & \\
\hline Middle & $3.70(1.8-8.275)$ & $0.001 *$ & & \\
\hline High & 1.00 (reference) & & & \\
\hline \multicolumn{5}{|l|}{ Income } \\
\hline $\begin{array}{l}\text { In debt/Just meet routine } \\
\text { expenses }\end{array}$ & $2.03(1.24-3.32)$ & $0.005 *$ & & \\
\hline $\begin{array}{l}\text { Meet emergencies/ save } \\
\text { money }\end{array}$ & 1.00 (reference) & & & \\
\hline Family stressors & $1.73(1.05-2.86)$ & 0.030* & $1.73(1.00-2.98)$ & $0.049 *$ \\
\hline \multicolumn{5}{|l|}{ Women's education } \\
\hline Illiterate & $2.78(1.59-4.58)$ & $<0.001 *$ & $2.2(1.20-4.02)$ & 0.010* \\
\hline Below secondary & $0.82(0.41-1.65)$ & 0.580 & $0.62(0.30-0.66)$ & 0.193 \\
\hline Secondary or above & 1.00 (reference) & & 1.00 (reference) & \\
\hline \multicolumn{5}{|l|}{ Husband's education } \\
\hline Illiterate & $3.91(2.10-7.28)$ & $<0.001 *$ & & \\
\hline Below secondary & $1.72(0.96-3.09)$ & 0.071 & & \\
\hline Secondary or above & 1.00 (reference) & & & \\
\hline \multicolumn{5}{|l|}{ Husband's occupation } \\
\hline $\begin{array}{l}\text { Unemployed/ Unskilled } \\
\text { worker }\end{array}$ & 1.00 (reference) & & 1.00 (reference) & \\
\hline Skilled worker & $0.62(0.37-1.06)$ & 0.081 & $0.68(0.39-12.0)$ & 0.188 \\
\hline Trades/business & $0.45(0.18-1.10)$ & 0.080 & $0.99(0.37-2.66)$ & 0.979 \\
\hline $\begin{array}{l}\text { Semiprofessional/ } \\
\text { Professional }\end{array}$ & $0.07(0.02-0.32)$ & $0.001 *$ & $0.14(0.31-0.66)$ & $0.012 *$ \\
\hline Age of wife & $1.02(0.95-1.1)$ & 0.633 & & \\
\hline Number of children & $1.01(0.88-1.3)$ & 0.527 & & \\
\hline \multicolumn{5}{|l|}{ Women's occupation } \\
\hline Housewife & 1.00 (reference) & & & \\
\hline Working & $0.79(0.33-1.89)$ & 0.598 & & \\
\hline \multicolumn{5}{|l|}{ Husband } \\
\hline Working abroad & 1.00 (reference) & & & \\
\hline Present & $1.63(0.99-2.70)$ & 0.057 & & \\
\hline Smoking & $1.72(1.08-2.75)$ & 0.024* & & \\
\hline \multicolumn{5}{|c|}{ 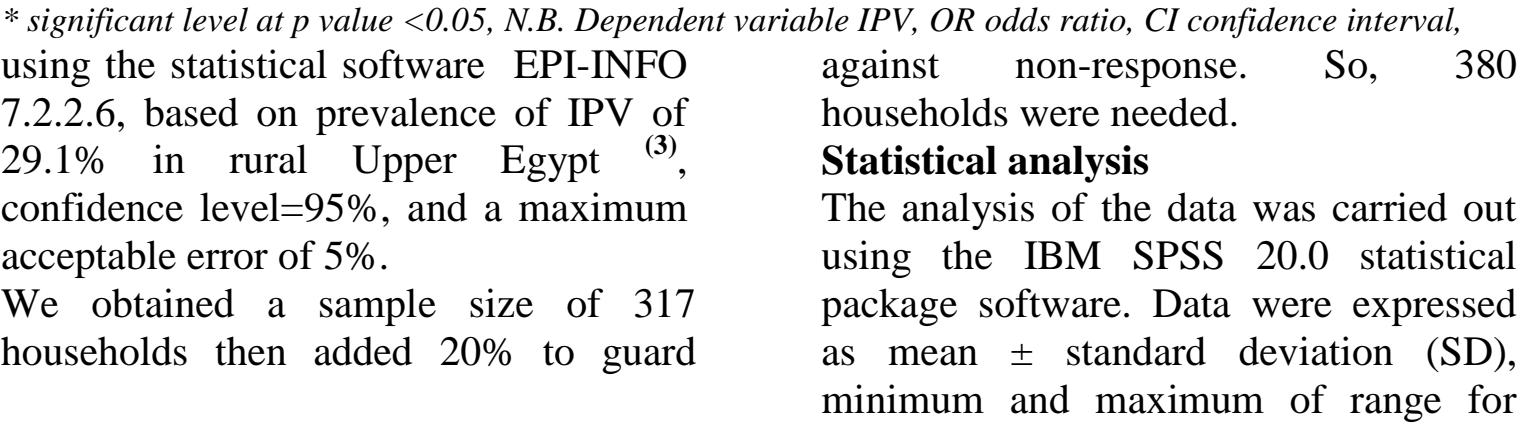 } \\
\hline The Egyptian Journal of Con & ity Medicine & ol. 39 & $\begin{array}{ll}\text { No. } 3 & \text { July }\end{array}$ & 2021 \\
\hline
\end{tabular}


quantitative parametric measures in addition to both number and percentage for categorized data. The Student t-test was used for comparison between two independent groups for parametric data, and the Chi-square test or Fisher's exact test were used to compare categorical variables. A binary logistic regression model (forward method) was used to evaluate the predictive value of the different variables, using IPV as the outcome. A p value of 0.05 or less was considered significant.

\section{Ethical consideration}

This study was approved by the Ethics Research Committee of Faculty of Medicine, Minia University. The studied group was informed about the nature and the purpose of the study and consent was taken before the interview. All data for the participants included in the study were kept confidential.

\section{Results}

In Table 1, the age of the studied women ranged between 19 and 35 years. The majority (91.6\%) were housewives. Nearly one fifth of them were illiterates, $16.6 \%$ have below secondary education, the majority have secondary education (57.9\%); and $7.1 \%$ completed education till university or higher. The average family size was $5.8 \pm 2.8$.

Regarding husbands of studied women, $13.9 \%$ were illiterates, $56.1 \%$ had secondary education or intermediate institute, and about $10.5 \%$ were university graduates or postgraduates. Only $1.3 \%$ were not employed. More than half $(54.7 \%)$ worked as skilled manual workers or farmers. Approximately one fourth $(25.5 \%)$ reported exposure to family stressors during the past 12 months.

In table 2, IPV exposure was higher among illiterate women (44.3\%) compared to below secondary (19\%) and secondary or above (22.3\%). IPV was higher among women married to less educated men.

A significant association was found between household income and IPV. About $45 \%$ of women belonged to families in debt, experience IPV while $12.9 \%$ of women in families able to save money reported IPV ( $p<0.001)$.

The mean household size was higher among women who reported IPV (6.5 \pm 3.6$)$ than who did not (5.5 \pm 2.5$)$ and the difference was statistically significant $(\mathrm{p}=0.003)$.

There was no significant difference between IPV and women's age, number of children, women's occupation. (Almost all women were housewives)

In Table 3, HFIAS score ranges from 0

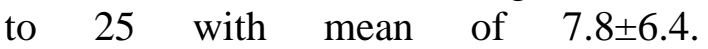
Approximately $69.7 \%$ of women in the study reported food insecurity, with $15.3 \%, 37.4 \%$ and $17.1 \%$ reporting mild, moderate and severe food insecurity. When compared with women in food secure households, women resided in food insecure households were more likely to suffer IPV (90.8\% compared to $7.8 \%)(\mathrm{p}<0.001)$.

In Table 4, risk factors found to be linked with IPV were food insecure households $(\mathrm{OR}=5.96)$, lower SES, households with lower income, women's education, factors related to the husband including lower education, occupation (having semiprofessional or professional job were associated with decreased reporting of IPV, OR= 0.07), smoking $(\mathrm{OR}=1.72)$ and past-year family stressors $(\mathrm{OR}=$ 1.73).

After adjustment, women from food insecure households were 5.04 times more likely to experience IPV than their counterparts in food secure households (95\% CI= 2.32-10.96). illiterate women have higher odds or reporting IPV experience compared to women with secondary or above education $(\mathrm{OR}=2.2)$. Women married to husbands having semiprofessional or professional job 
were associated with decreased reporting of IPV $(\mathrm{OR}=0.012)$. In addition, the odds of physical IPV exposure were 1.73 times higher among those who experienced family stressors $(95 \% \mathrm{CI}=$ 1-2.98) compared to those who did not experience family stressors.

\section{Discussion}

Women, worldwide including Egypt, suffer from serious public health issues as food insecurity and violence. Violence against women is a violation of their basic human rights. ${ }^{1}$ In the current study, about $25.8 \%$ of currently married women reported exposure to spousal violence. A similar percentage $(25.2 \%)$ was reported in 2014 EDHS rising to $29.1 \%$ in rural Upper Egypt. ${ }^{3}$ A study conducted by Shaikh et al. (2017) in rural Minia, reported higher prevalence of IPV (66.1\%), however they reported lifetime exposure to IPV, physical, sexual or psychological $^{20}$, while the current study asked about physical violence exposure during last 12 months.

In the region of North African/Middle Eastern the prevalence of IPV ranges between 30 and $40 \%{ }^{21}$ In a systematic review conducted by ${ }^{(1)}$ it was found that one-third $(30 \%)$ of women have been exposed to physical and/or sexual violence perpetrated by their intimate partner. Mostly, physical violence was perpetrated against less educated, less income women and lower SES, similar findings reported in a study conducted in Minia by Yount (2005) who reported that SES and household wealth is negatively associated with physical abuse. ${ }^{22}$

HFI is often a key marker of violence vulnerability. We found that food insecurity was significantly associated with current violence even after adjusting for socio-economic status. In the final model, women experiencing food insecurity, and living in low SES households were more likely to experience IPV.
This finding is consistent with previous cross-sectional studies ${ }^{5,23}$, even in highincome countries. ${ }^{9}$ Others related food insecurity with emotional violence rather than physical violence ${ }^{(9)}$. In longitudinal studies, a strong, positive association was reported between food insecurity and violence against women with and at risk for HIV and that cumulative exposure to food insecurity was a stronger predictor of violence than at a single time point. ${ }^{8}$ In another longitudinal study on 2,479 men from South Africa investigated whether food insecurity changes influenced men's IPV perpetration over time and concluded that food insecurity had small but persistent longitudinal effects on men's perpetration of IPV. ${ }^{24}$ Moreover, a randomized controlled trial of a cash and food transfer program in Ecuador showed that transfers reduced physical or sexual violence by $30 \%$ through reducing conflicts over money and financial stress $^{25}$, implying that attention must be given to prevent IPV through increasing the household's food security.

Relation between violence and food insecurity is bidirectional. Violence can be viewed as a cause or a result of food insecurity. Food insecurity may contribute to the experience of IPV in a number of ways. Stress induced by food insecurity may act as a driver for violence in families ${ }^{(8)}$. Moreover, it is difficult for women to leave abusive behavior of their husband because of their dependence on them for food ${ }^{(26)}$. Power inequality put women at an increasing risk of food insecurity. ${ }^{12}$

IPV leads to food insecurity through impairing mother's ability to manage obtaining adequate food mediated by negative impact on mental health or through economic abuse and controlling access to financial resources. $5,12,13$

Poverty may be a strong underlying driver of men's IPV perpetration. North American cross-sectional research shows 
that men who are unemployed have higher rates of perpetrating $\mathrm{IPV}^{27}$, as do men of households with lower income. ${ }^{28}$ Mental health may mediate the association between food insecurity and violence where poor mental health elicited by food insecurity may trigger violence. Men bear the responsibility of food provision for the family, inability to meet their family needs may result in mental distressed and increased quarreling between couples which eventually lead to in perpetrating violence. $^{29}$ Reciprocal association may result when violence leads to food insecurity either by negative effect on mental health leading to poor management of household resources or controlling of financial resources by other partner as a form violence or control. $^{10,13}$

Although association between smoking habit of husband and IPV was not significant in the final model, previous studies showed that smoking was strongly associated with IPV. ${ }^{30,31}$ Direct mechanisms that smoking may lead to IPV are by affecting cognition, reducing self-control, perpetuating aggression ${ }^{30}$ and indirectly through the stress and financial burden generated through spending money on cigarettes instead of being spent on household essentials like food thereby, further increasing the risk of violence and conflict.

Family stressors other than food insecurity were found to be associated with higher odds of IPV. Previous study has linked exposure to stressors as utilities nonpayment, housing nonpayment, food insecurity, and disconnected phone service with perpetrating physical IPV. ${ }^{32}$

Food insecurity can be used as a risk indicator for IPV experienced by women. We need to understand the factors that place women at greatest risk, thus facilitating intervention development.

\section{Public health implications}

Given the association between food insecurity and violence, interventions to enhance food security may help prevent violence. Programs targeting food insecure families are as needed as women empowerment programs. To address food insecurity programs like food supplementation programs, subsidized food targeted to vulnerable populations and supplemental nutritional assistance are recommended. Programs and policies to increase livelihood options involving new jobs or agricultural work are more appropriate than brief interventions.

There could also be a requirement for multi-level programs that merge structural-level interventions with interpersonal interventions to enhance couple communication around financial stress and food acquisition which could reduce violence perpetrated against through enhance communication and problem-solving. Healthcare providers also have important role in addressing food insecurity through screening during clinical setting and referral to appropriate services if available. Efforts should be made to empower women socially and economically to protect them from food insecurity as well as violence.

\section{References}

1. WHO. Global and regional estimates of violence against women: prevalence and health effects of intimate partner violence and non-partner sexual violence. Geneva, Switzerland: WHO, The Department of Reproductive Health and Research (RHR). Available

at: https://www.who.int/reproductivehealth/ publications/violence/9789241564625/en / . Accessed on 10/11/2018: World Health Organization; 2013.

2. UNFPA, NPC, Baseera. Population Situation Analysis: Egypt 2016. 2016:Available at: https://egypt.unfpa.org/sites/default/files/pub 
-pdf/PSA\%20Final.pdf. Accessed on: 4/8/2018.

3. Elzanaty, Associates. Egyptian demography and Health Survey 2014, MOHP, Egypt. Available at https://dhsprogram.com/pubs/pdf/FR302/FR 302.pdf. Accessed in May 2018. 2015.

4. Nossier SA. Violence against women in the Arab world. The Journal of The Egyptian Public Health Association. 2015;90(3):85-6.

5. Ribeiro-Silva RdC, Fiaccone RL, Barreto ML, Santana MLP, Santos SMCd, Conceição-Machado MEPd, et al. The association between intimate partner domestic violence and the food security status of poor families in Brazil. Public Health Nutrition. 2015;19(7):1305-11.

6. Diamond-Smith N, Conroy AA, Tsai AC, Nekkanti M, Weiser SD. Food insecurity and intimate partner violence among married women in Nepal. J Glob Health. 2019;9(1):010412-.

7. Hatcher AM, Stöckl H, McBride R-S, Khumalo M, Christofides N. Pathways From Food Insecurity to Intimate Partner Violence Perpetration Among Peri-Urban Men in South Africa. American Journal of Preventive Medicine. 2019;56(5):765-72.

8. Conroy AA, Cohen MH, Frongillo EA, Tsai AC, Wilson TE, Wentz EL, et al. Food insecurity and violence in a prospective cohort of women at risk for or living with HIV in the U.S. PLOS ONE. 2019;14(3):e0213365.

9. Gibbs A, Corboz J, Jewkes R. Factors associated with recent intimate partner violence experience amongst currently married women in Afghanistan and health impacts of IPV: a cross sectional study. BMC Public Health. 2018;18(1):593.

10. Johnson AD, Markowitz AJ. Food Insecurity and Family Well-Being Outcomes among Households with Young Children. The Journal of Pediatrics. 2018;196:275-82. 11. Rahman M, Nakamura K, Seino K, Kizuki M. Intimate partner violence and chronic undernutrition among married Bangladeshi women of reproductive age: are the poor uniquely disadvantaged? European Journal Of Clinical Nutrition. 2012;67:301. 12. Ricks JL, Cochran SD, Arah OA, Williams JK, Seeman TE. Food insecurity and intimate partner violence against women: results from the California Women's Health Survey. Public health nutrition. 2016;19(5):914-23.

13. Hernandez DC, Marshall A, Mineo C. Maternal Depression Mediates the Association Between Intimate Partner Violence and Food Insecurity. Journal of Women's Health. 2014;23(1):29-37.

14. Lentz EC. Complicating narratives of women's food and nutrition insecurity: Domestic violence in rural Bangladesh. World Development. 2018;104:271-80.

15. Straus MA, Hamby SL, Boney-McCoy $\mathrm{S}$, Sugarman DB. The revised conflict tactics scales (CTS2) development and preliminary psychometric data. Journal of family issues. 1996;17(3):283-316.

16. El-Gilany A, El-Wehady A, El-Wasify M. Updating and validation of the socioeconomic status scale for health research in Egypt. Eastern Mediterranean Health Journal. 2012;18(9):962.

17. Fahmy S, El-Sherbini A. Determining simple parameters for social classifications for health research. Bulletin of the High Institute of Public Health. 1983;13:95-108.

18. Coates J, Swindale A, Bilinsky P. Household Food Insecurity Access Scale (HFIAS) for measurement of food access: indicator guide. Washington, DC: Food and Nutrition Technical Assistance Project, Academy for Educational Development. 2007:34.

19. Naja F, Hwalla N, Fossian T, Zebian D, Nasreddine L. Validity and reliability of the Arabic version of the Household Food Insecurity Access Scale in rural Lebanon. Public Health Nutrition. 2014;18(2):251-8.

20. Shaikh AK, Pearce B, Yount KM. Effect of Enabling Resources and Risk Factors on the Relationship between Intimate Partner Violence and Anxiety in Ever-Married Women in Minya, Egypt. Journal of Family Violence. 2017;32(1):13-23.

21. Devries KM, Mak JY, Garcia-Moreno C, Petzold M, Child JC, Falder G, et al. The global prevalence of intimate partner violence against women. Science. 2013;340(6140):1527-8.

22. Yount KM. Resources, Family Organization, and Domestic Violence Against Married Women in Minya, Egypt. 
Journal of Marriage and Family. 2005;67(3):579-96.

23. Jewkes R, Fulu E, Tabassam Naved R, Chirwa E, Dunkle K, Haardörfer R, et al. Women's and men's reports of past-year prevalence of intimate partner violence and rape and women's risk factors for intimate partner violence: A multicountry crosssectional study in Asia and the Pacific. PLoS medicine. 2017;14(9):e1002381-e.

24. Hatcher A, Neilands T, Rebombo D, Weiser S, Christofides N. Longitudinal effects of poverty on men's perpetration of partner violence in South Africa.

25. Buller AM, Hidrobo M, Peterman A, Heise L. The way to a man's heart is through his stomach?: a mixed methods study on causal mechanisms through which cash and in-kind food transfers decreased intimate partner violence. BMC Public Health. 2016;16(1):488.

26. Miller CL, Bangsberg DR, Tuller DM, Senkungu J, Kawuma A, Frongillo EA, et al. Food insecurity and sexual risk in an HIV endemic community in Uganda. AIDS and Behavior. 2011;15(7):1512-9.

27. Caetano R, Vaeth PA, Ramisetty-Mikler S. Intimate partner violence victim and perpetrator characteristics among couples in the United States. Journal of Family Violence. 2008;23(6):507-18.
28. Ranganathan M, Knight L, Abramsky T, Muvhango L, Polzer Ngwato T, Mbobelatsi $\mathrm{M}$, et al. Associations Between Women's Economic and Social Empowerment and Intimate Partner Violence: Findings From a Microfinance Plus Program in Rural North West Province, South Africa. Journal of Interpersonal Violence. 2019:0886260519836952.

29. Cardoso LF, Gupta J, Shuman S, Cole H, Kpebo D, Falb KL. What factors contribute to intimate partner violence against women in urban, conflict-affected settings? Qualitative findings from Abidjan, Cote d'Ivoire. Journal of Urban Health. 2016;93(2):364-78.

30. Ali NS, Ali FN, Khuwaja AK, Nanji K. Factors associated with intimate partner violence against women in a mega city of South-Asia: multi-centre cross-sectional study. Hong Kong Medical Journal= Xianggang Yi Xue Za Zhi. 2014;20(4):297.

31. Ntaganira J, Muula A, Siziya S, Stoskopf C, Rudatsikira E. Factors associated with intimate partner violence among pregnant rural women in Rwanda. 2009.

32. Schwab-Reese LM, Peek-Asa C, Parker E. Associations of financial stressors and physical intimate partner violence perpetration. Injury epidemiology. 2016;3(1):6. 